\title{
PERSPECTIVE
}

\section{Sri Lanka Journal of Surgery : chronicles of half a century}

\author{
Nuwanthika Karunarathne ${ }^{1}$, Ajith Malalasekera ${ }^{2}$ \\ ${ }^{1}$ Lady Ridgeway Hospital for Children, Colombo, Sri Lanka \\ ${ }^{2}$ Department of Anatomy, Faculty of Medicine, University of Colombo, Sri Lanka
}

\section{CHIRURGIAE PROGRESSUS CAUSA \\ " For the progress of surgery"}

History is made on pillars of time and perseverance. It's built with hope, knowledge, wisdom and modesty. Such was our beginning, as the Sri Lanka journal of Surgery in 1970. A wonderful mix of all that and more. The College of Surgeons was founded in 1971 in the era of bell-bottoms and disco and also amidst brewing political unrest. It had a rather muted commencement without any assets but the eagerness of the generation of surgeons in that era.

Founding the Sri Lanka Journal of Surgery in 1970, was a fundamental milestone in the evolution of Surgery and surgical education in Sri Lanka. It was called the Ceylon Journal of Surgery at the outset and became the Sri Lanka Journal of Surgery in 1982. It has, in its 51-year history, done a vital, prudent service to the amelioration of surgical research and training.

The first issue was published in 1970, and Dr Chummy S Sinnatamby held the chair as the chief editor with an advisory editorial board of 8 eminent surgeons of that era which included Dr S A Cabraal, Dr A T S Paul, Dr R A Navaratna. The foreword was provided by Sir Thomas Holmes Sellors, the president of the Royal College of Surgeons of England indicating the amicable connection between the two colleges which is still present to this day.

The 1st article of its foremost issue was on subdural haematoma by Dr Darrel Weinman, followed by articles covering paediatric surgery and parenteral nutrition. This issue was mainly focused on the thyroid gland and its benign and malignant pathologies, with a symposium exploring the roots of its epidemiology, surgical management and radiotherapy for thyroid carcinoma. With that debut issue, it embarked on a long journey to enrich and empower surgical education in Sri Lanka. At the outset a single annual issue was published but currently we publish 4 issues per year, one of which coincides with the Annual scientific sessions of the College of Surgeons of Sri Lanka.

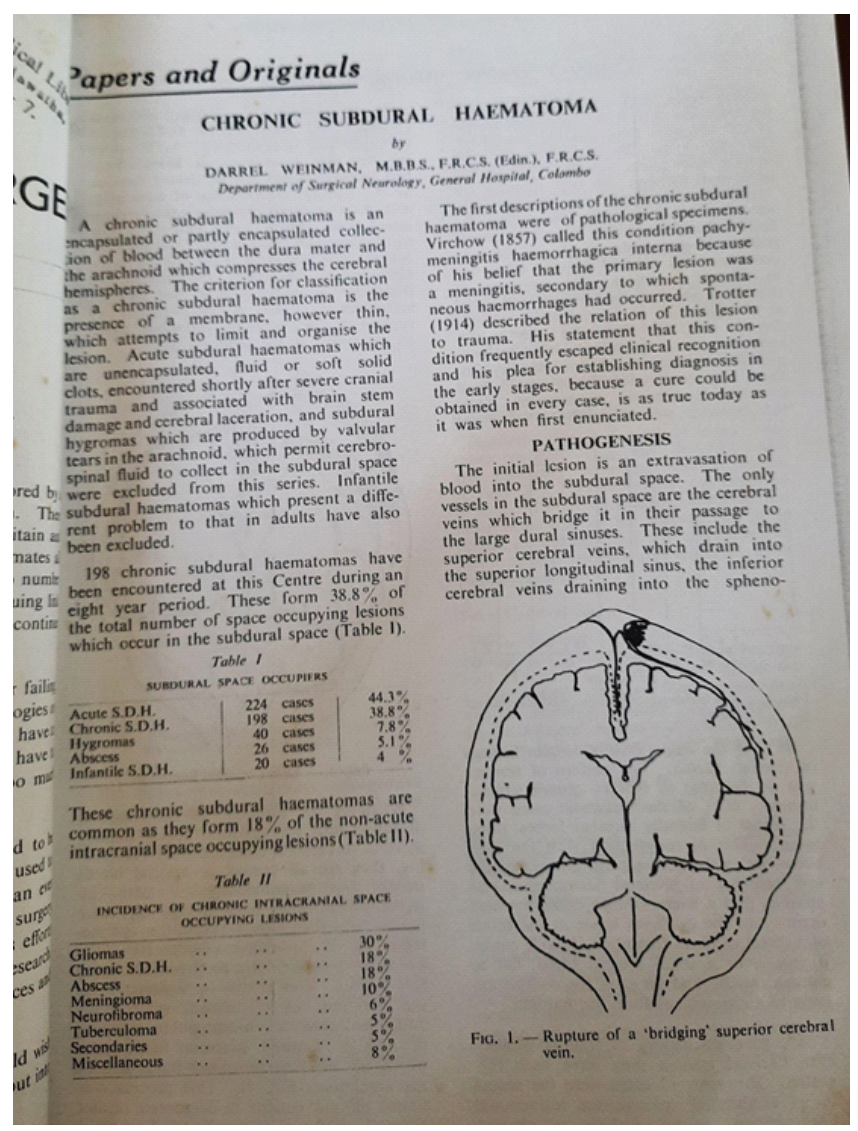

The 1st issue was printed by Kularatne and Company limited at Colombo 10, later for a great number of years the printing courtesy was held by Ananda press, Colombo. Currently it is published online at the Sri Lanka Journals Online platform (https://www.sljol.info/).

Correspondence: Ajith Malalasekera

E-mail: ajith@anat.cmb.ac.lk

(iDhttps://orcid.org/0000-0003-1274-8254

Received: 21-11-2021 Accepted: 21-11-2021

DOI: http://doi.org/10.4038/sljs.v39i3.8920

The Sri Lanka Journal of Surgery 2021; 39(3): 124-130 


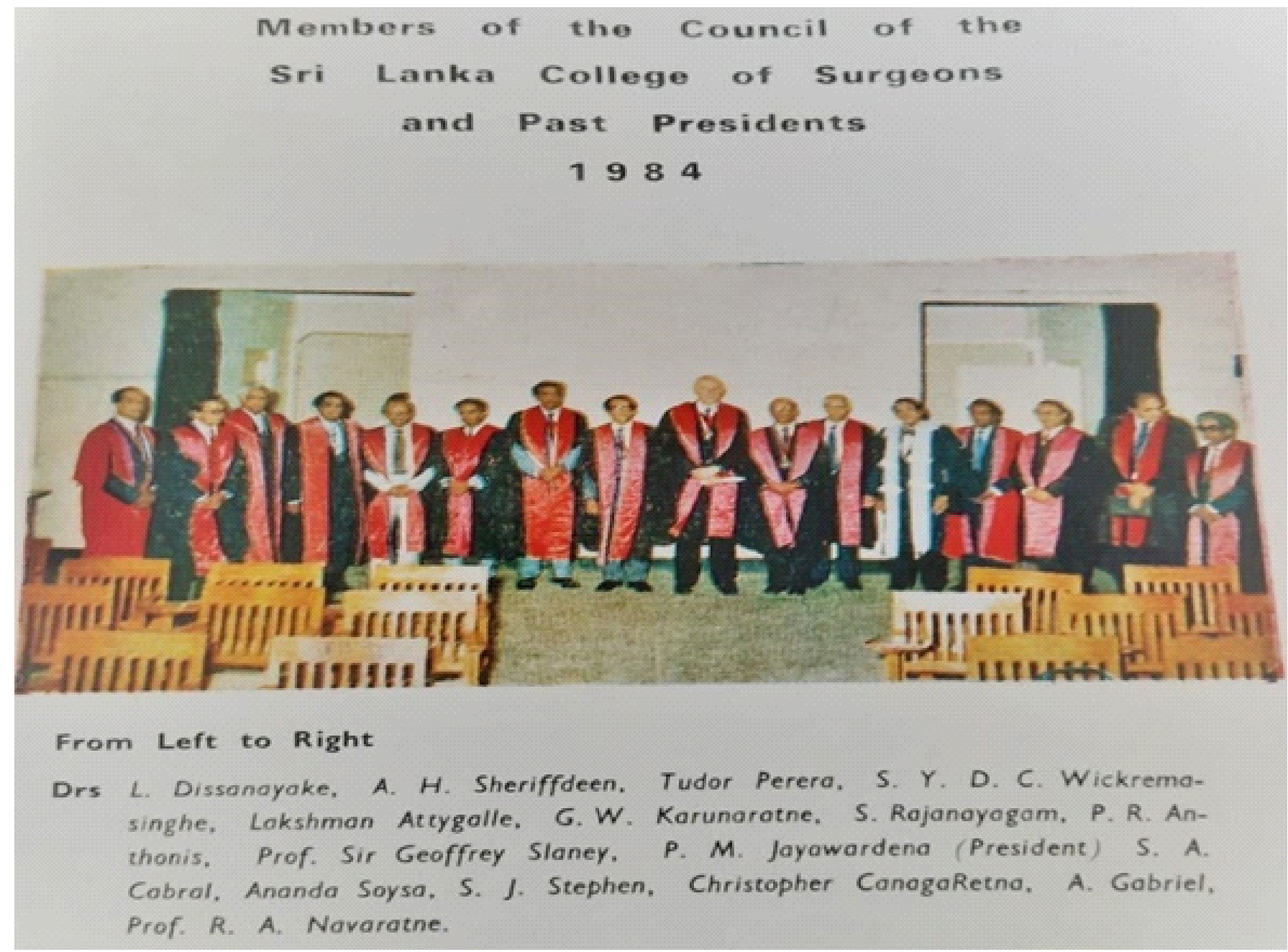

Editors-in-chief of Sri Lanka Journal of Surgery throughout the years

1970

C S Sinnatamby

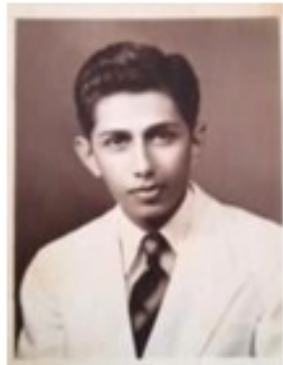

1971-1972

A Gabriel

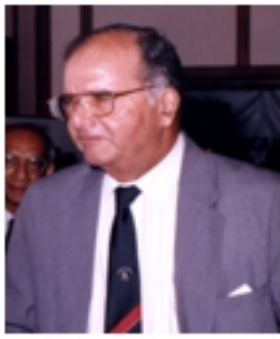


1973-1983 C S Sinnatamby

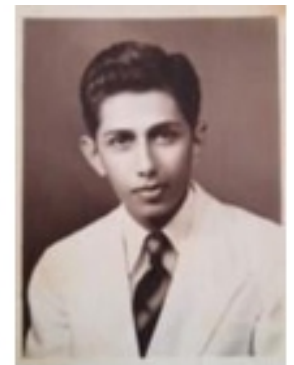

1984

J T Fernado

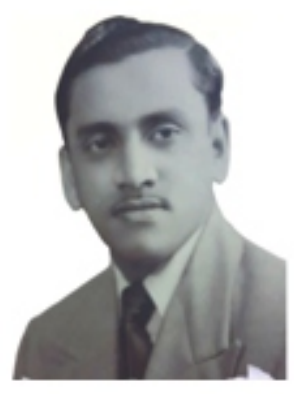

$1985-1990$

Christopher Canagaretne

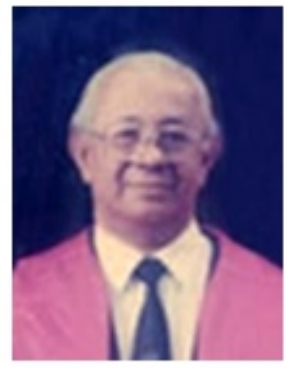

1991-1992 A Gabriel

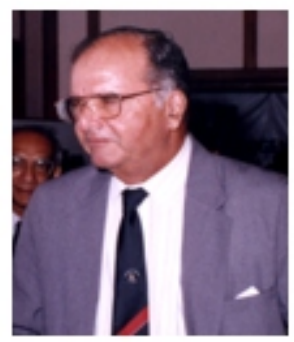

1993

S J Stephen

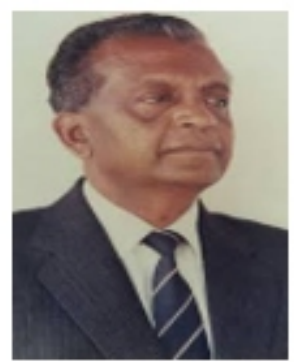

1994-1998

SC Paul

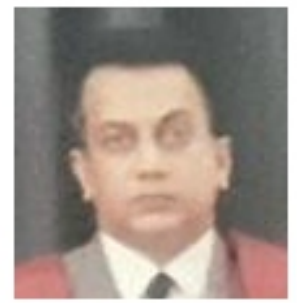



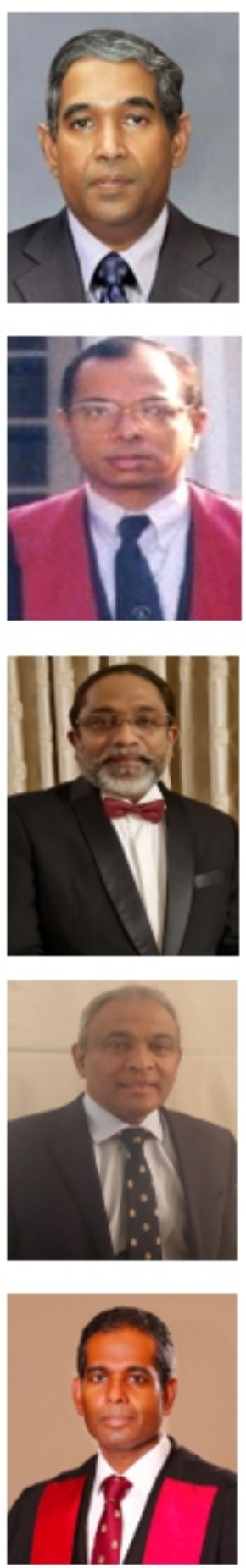
Throughout these 50 years, the pages of the journal have made home for audits, debates, advances, innovations, controversies and recognition - all of which makes up a wholesome, dynamic journal on its way to the zenith.

It has covered many topics of surgery and its associated sciences with comprehensive discussions aligned with the prevailing discoveries and advances. It has been a cordial podium to its international contributors and has published articles from renowned personalities such as Norman L. Browse, Terrence L Kennedy, John Gillingham and thus, added more hues of elegance and grace to its pages. It had been a sturdy cornerstone for trainees in surgery which provided them with the broad wisdom to grow and a welcoming platform to brandish their speculations.
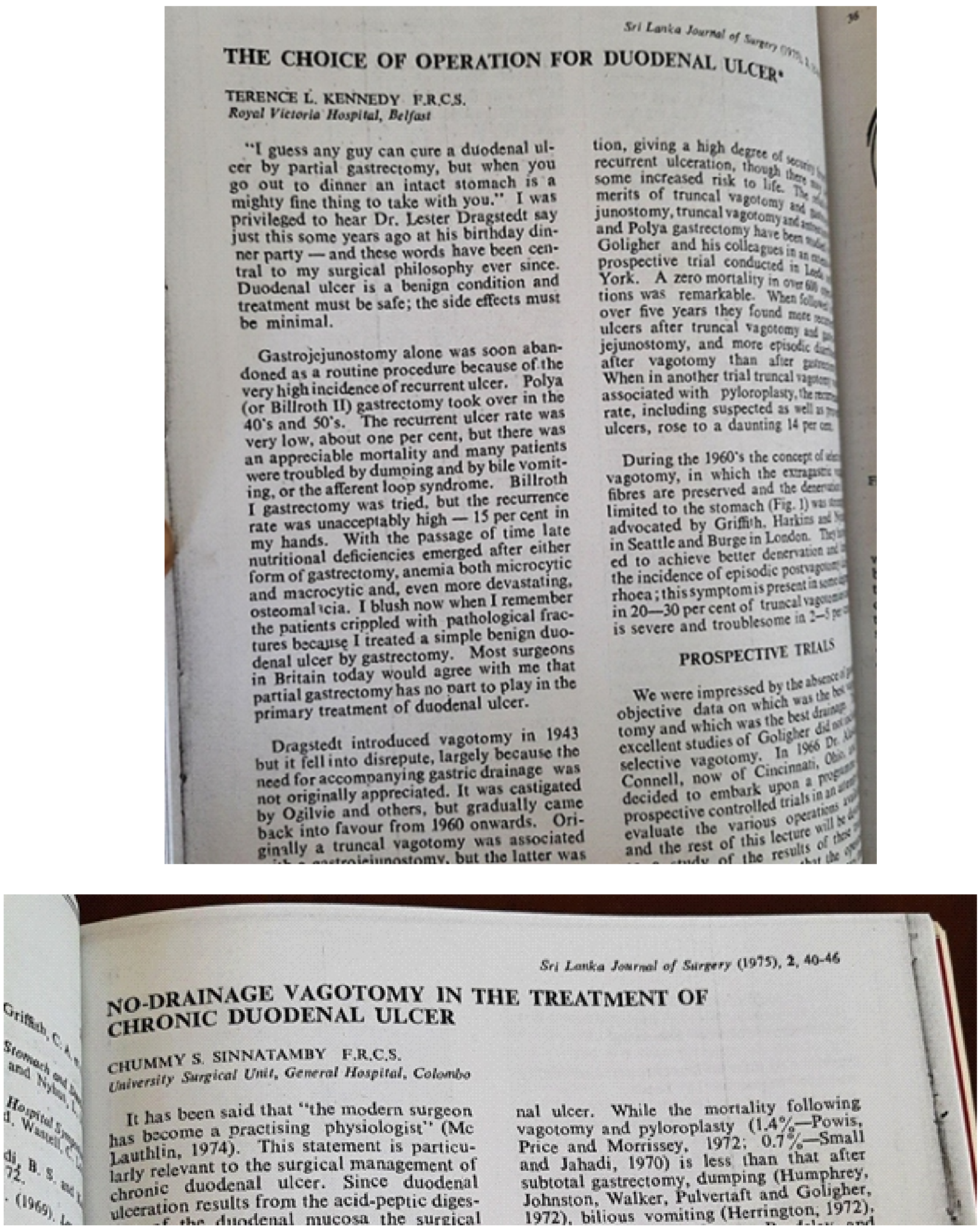

The Sri Lanka Journal of Surgery 2021; 39(3): 124-130 


\section{With 50 years behind us...}

Half a century later, we are a journal with peer reviewed articles in the form of leading articles, review articles, perspectives, brief reports, case series and reports in the field of surgery and its related surgical sciences - accomplishing its evergreen mission 'to reach the highest standard of scientific surgical practice by dissemination of high quality scientific information and to foster and promote the growth of scientific surgery.

Sri Lanka Journal of Surgery has a benevolent open access policy for its articles elaborating its principle to augment greater global exchange of knowledge. The journal adheres to the publication ethics as portrayed by the Committee on Publication Ethics (COPE) and is a member of this organisation. It is listed as an ICMJE journal which follows its recommendations (ICMJE recommendations) on Conduct, Reporting, Editing and Publication of Scholarly Work in Medical Journals. It is indexed on the Directory of Open Access Journals and Google Scholar. Sri Lanka Journal of Surgery has become a point of reference for aspirations amongst the surgical trainees as well as a motif of surgical excellence in Sri Lanka. It has and will continue to persevere for the betterment of Surgical knowledge not only in Sri Lanka but also at a broader global platform.

Needless to say, it is not an easy task to construct a successful journal to its current level within 50 years. Thus, the esteemed editors-in-chief, editorial boards, the international advisory panels, its multitude of reviewers and authors who have nurtured the journal on its journey with each stride forward with a sense of utmost responsibility and unwavering perseverance are remembered today with unconditional respect and gratitude.

\section{Editorial Board 2021}

\section{Ajith Malalasekera Editor in Chief}

\section{Prof Sivasuriya Sivaganesh}

Dr Hiran Amarasekara

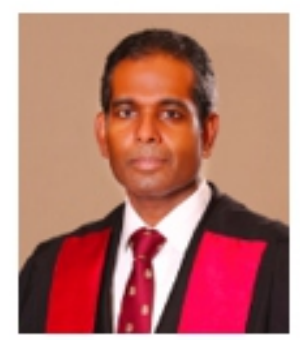

Prof Kemal I. Deen
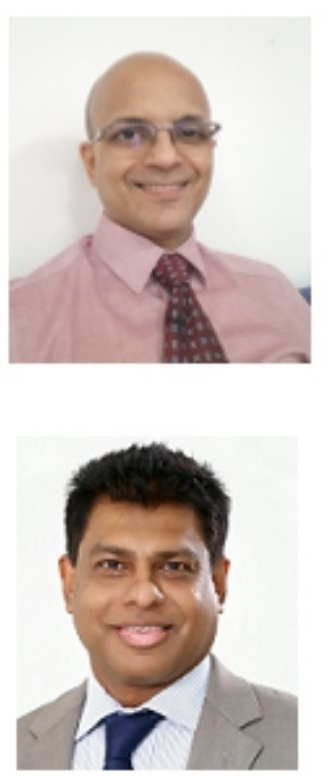
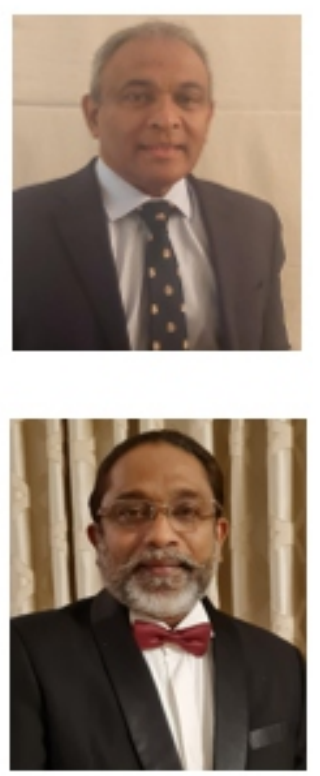

Dr Naomal Perera

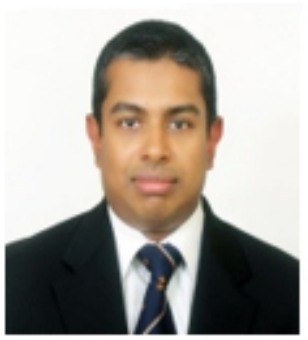


Dr Sanjeewa Seneviratne

Dr Dileepa Ediriweera

Dr Rasika Jayatillake

Dr Kesara Rathnatunga

I

Dr Nuwanthika Karunaratne Assistant editor

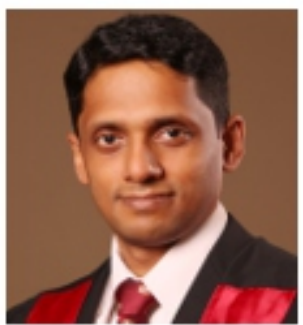

Dr Pramodh Chandrasinghe

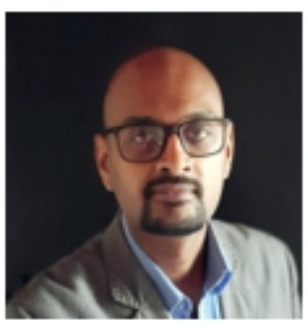

Dr Dakshitha Wickramasinghe
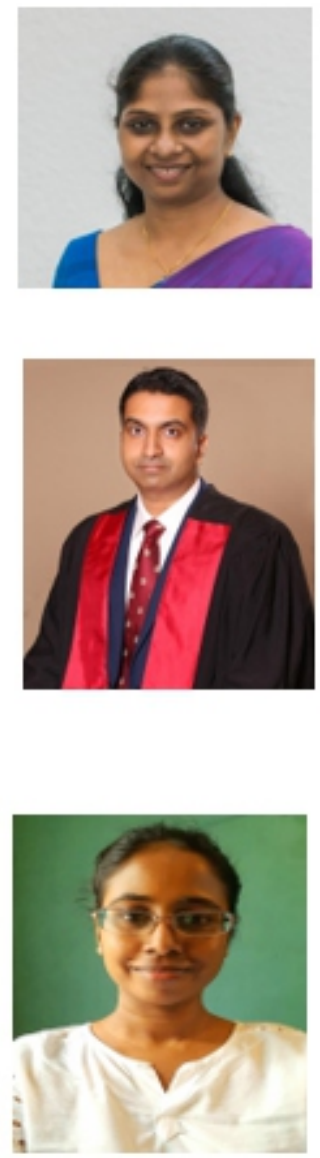

Dr Gayan Ekanayake

Dr Ruvini Abeygunaratne
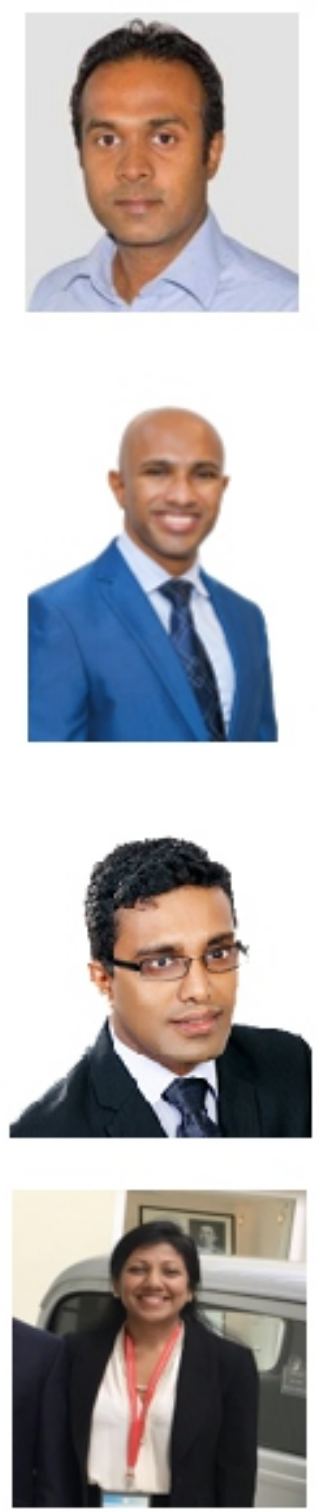

Ms Nethishika Fernando

Editorial Assistant

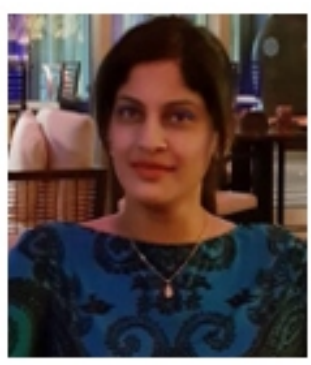

